\title{
Friend or foe? Carbon monoxide and the mitochondria
}

\author{
Nils Schallner ${ }^{1,2}$ and Leo E. Otterbein ${ }^{1 *}$ \\ 1 Department of Surgery, Beth Israel Deaconess Medical Center, Harvard Medical School, Boston, MA, USA \\ ${ }^{2}$ Department of Anesthesiology and Intensive Care Medicine, University Medical Center Freiburg, Freiburg, Germany \\ *Correspondence: lotterbe@bidmc.harvard.edu \\ Edited by: \\ Pamela Boon Li Pun, Defence Medical and Environmental Research Institute, Singapore \\ Reviewed by: \\ Nazareno Paolocci, Johns Hopkins University, USA \\ Gregory M. Vercellotti, University of Minnesota, USA
}

Keywords: heme, heme oxygenase, bioenergetics, hemoprotein, CO-RM

\section{PHYSIOLOGY OF CARBON MONOXIDE}

The longstanding perception of the gas carbon monoxide (CO) as an odorless and colorless "silent killer" began to attract the attention of the public with the arrival of the industrial age in the beginning of the twentieth century (Douglas et al., 1912). In fact, carbon monoxide has been present in all societies since the discovery of fire, yet it was John Haldane in the early part of the twentieth century that declared $\mathrm{CO}$ a lethal poison based on his investigations of mine disasters. American Indians knew that in addition to warmth, gathering around a fire brought calming and tranquil effects, something we now attribute to neuroactive properties of the gas. Poisonings from exhaust certainly continue to pose significant problems, as it did in the coal mine explosions, but it remains unclear why the $>500$ other molecules that emerge from combustion, many of which are carcinogens, are largely ignored, yet pose just as great a risk as CO. It was not until the late 1960's that endogenous production of $\mathrm{CO}$ was discovered as a result of the catabolism of heme (Sjostrand, 1949; Coburn et al., 1963), suggesting a physiological role for this simple, diatomic gas. Decades after these findings were reported, investigators noted that levels of $\mathrm{CO}$ were significantly elevated in the exhaled breath of hospitalized patients (Vos et al., 2009; Cheng et al., 2010; James et al., 2010; Zhang et al., 2010). The illnesses were wide-ranging, yet it was clear that CO levels would decrease as the pathology resolved. How then can it be explained that $\mathrm{CO}$ is toxic if the body generates it physiologically and even more puzzling, generates more when in a compromised state? The answer may lie in the ancient organelle known as the mitochondria, an evolutionary endosymbiont originating from proteobacteria whose singular responsibility is to generate energy for the cell. It relies principally on the presence of gases in the elegant transfer of electrons among the oxidases contained within its membranes.

The targets for $\mathrm{CO}$ are ostensibly clear. CO binds rapidly and with high affinity to heme-containing proteins such as hemoglobin, the mitochondria oxidases or the enzymes necessary for reactive oxygen species generation. CO competes with oxygen transport and cellular respiration and it is perhaps in this primitive symbiotic organelle, among the numerous hemoprotein complexes competing with the other bioactive gases including nitric oxide, oxygen, hydrogen sulfide and carbon dioxide that $\mathrm{CO}$ integrates itself and impacts cellular physiology. The body of evidence supporting a physiological role for $\mathrm{CO}$ is immense and continues to move forward as $\mathrm{CO}$ is being evaluated in ongoing clinical trials (www.clinicaltrials. gov, Identifier: NCT 01727167, 00094406, 00122694, 01214187, 01050712, 01050933, 01523548, and 00531856).

The endogenous generation of $\mathrm{CO}$ as described by Tenhunen et al. (1968) occurs through the enzymatic degradation of heme by the heme oxygenases, enzymes present in all cells that convert heme into biliverdin, iron and CO. Like CO, it has become undeniably clear that each catalytic product has important physiological functions beyond serving as byproducts. Two isoforms of heme oxygenase exist: heme oxygenase
1 (Hmox-1), which is expressed ubiquitously and is highly inducible by an array of stimuli, and the constitutive heme oxygenase-2 (Hmox-2) isoform, predominantly expressed in neurons, the testes, and the vasculature. Induction of $\mathrm{HO}$ 1 has proven to be a strong cytoprotectant while deficiency in HO-1 leads to aggravated disease states, even in humans (Poss and Tonegawa, 1997; Otterbein et al., 1999; Park et al., 2007; Tsuchihashi et al., 2007; Chen et al., 2009; Wang et al., 2009, 2012; Yin et al., 2010; Ferenbach et al., 2011; Ogawa et al., 2011; Zhang et al., 2012).

\section{CO AS A THERAPEUTIC AGENT}

There is compelling pre-clinical data proving the salutary effects of exogenous CO application. (Motterlini and Otterbein, 2010) CO has been shown to regulate immune responses (Freitas et al., 2006), cell survival (Song et al., 2003) and regeneration (Lin et al., 2009; Lakkisto et al., 2010) as well as proliferation (Wegiel et al., 2013). CO is homeodynamic in that it serves the need of the tissue. There are reports that it is both anti- and proinflammatory (Lee et al., 2007; Beckman et al., 2009), pro- and anti-apoptotic (Song et al., 2004; Vieira et al., 2008) and proand anti-proliferative (Otterbein et al., 2003; Kuramitsu et al., 2011). One of the primary sites in the body where $\mathrm{CO}$ is believed to be most toxic is the brain and this is based on weak studies with lack of rigor and proper controls. CO is clearly neuroprotective in various neuronal injury models (Vieira et al., 2008; Zeynalov and Dore, 2009; Wang et al., 2011; Yabluchanskiy et al., 2012; Schallner 
et al., 2013) and extensive safety trials in humans have been completed without a single sign of toxicity at carboxyhemoglobin levels of 12-15\% (Mayr et al., 2005; Bathoorn et al., 2007). Most importantly, no negative influence on cognitive function was detected. Collectively, the clinical testing is safe with quantitative delivery of inhaled $\mathrm{CO}$ relative to body weight and independent of the respiratory rate has also been developed (Motterlini and Otterbein, 2010). The challenges of establishing $\mathrm{CO}$ as a gaseous pharmaceutical triggered an onslaught of research surrounding alternative routes of $\mathrm{CO}$ application. Carbon Monoxide Releasing Molecules (CO-RMs) emerged in 2002 pioneered by Roberto Motterlini (Motterlini et al., 2002). CO-saturated pegylated hemoglobins have emerged that also modulate inflammation and vasoocclusion in murine models of sickle cell anemia (Belcher et al., 2013). These CO carriers, or pro-drugs, release $\mathrm{CO}$ following well-defined kinetics and have been characterized to deliver CO to target tissues in several in vitro(Clark et al., 2003; Motterlini et al., 2005; Bani-Hani et al., 2006; Megias et al., 2007; Urquhart et al., 2007) and in vivo (Tayem et al., 2006; De Backer et al., 2009; Tsoyi et al., 2009; Vadori et al., 2009) studies, exerting biological effects much like inhaled gas (BaniHani et al., 2006; Yabluchanskiy et al., 2012).

\section{CO AND THE MITOCHONDRIA}

Despite profound pre-clinical evidence of efficacy, the molecular mechanisms by which $\mathrm{CO}$ exerts its protective effects in a diverse array of animal models remains poorly characterized with numerous and confounding molecular targets described (Motterlini and Otterbein, 2010). The high affinity for heme makes any cellular hemecontaining protein a potential target for $\mathrm{CO}$, including soluble guanylate cyclase (sGC) (Verma et al., 1993; Schallner et al., 2013), NO-synthase (Zuckerbraun et al., 2003; Marazioti et al., 2011), NADPH oxidase (Taille et al., 2005) and NPAS-2 (Dioum et al., 2002) among a multitude of others. While a unifying signature is lacking, the single-most implicated target is the mitochondria. This seems paradoxical at first sight since inhibition of mitochondrial respiration via CO binding to components of the mitochondrial electron transfer chain, has been looked at as being responsible for the toxicity seen after $\mathrm{CO}$ poisoning. Against this dogma, however, $\mathrm{CO}$ exposure clearly influences cellular bioenergetics in the context of salutary effects, paradoxically increasing $\mathrm{O}_{2}$ bioavailability and consumption, which in turn reduces injury-related organ damage (Tsui et al., 2007; Lancel et al., 2009). $\mathrm{CO}$ increases mitochondrial generation of reactive oxygen species (Chin et al., 2007; Zuckerbraun et al., 2007) and mitochondrial biogenesis, (Suliman et al., 2007; Piantadosi et al., 2008) which likely go hand-in-hand to influence the vast array of cellular downstream targets that have been linked to the beneficial effects of CO (Motterlini and Otterbein, 2010). We speculate that $\mathrm{CO}$ alters oxygen sensing and exerts a "pseudo-hypoxic" state, providing a powerful cellular impact toward re-generation and increasing the cellular energy supply that leads to improved survival in the presence of cell stress and injury.

\section{CONCLUSIONS AND PERSPECTIVE}

The name mitochondria originated from the Greek "mitos" meaning thread and "chondros" meaning granule, which referred to their structural appearance. They were first called "bioblasts" which is perhaps a more accurate designation giving the impression of explosive behavior while generating critical energy for the cell. Mitochondria are comprised of lipid bilayers and proteins like other cellular compartments including the Golgi, endoplasmic reticulum and the nucleus. The mitochondria rely to a large extent on the interrelationships among the gases, primarily $\mathrm{O}_{2}$ and $\mathrm{CO}_{2}$. These gases serve as the fundamental molecules involved in the energy-transduction system that ultimately results in generation of life-sustaining ATP. It has become clear, however that $\mathrm{O}_{2}$ and $\mathrm{CO}_{2}$ are not alone in dictating cellular physiologic and pathophysiologic responses. Much like the complexities of signal transduction, gene regulation and metabolic pathways, the cellular gases $\mathrm{CO}$ and its sister gases $\mathrm{NO}$ and $\mathrm{H}_{2} \mathrm{~S}$ are critically integrated into the function of mitochondria and therein the overall health of the organism.

\section{ACKNOWLEDGMENTS}

Grants: German Research Foundation (DFG) SCHA1838/2-1 to Nils Schallner. We thank the Julie Henry Fund at the Transplant Center of the BIDMC for their support. Leo E. Otterbein has a visiting professorship at Aston University, Birmingham, UK.

\section{REFERENCES}

Bani-Hani, M. G., Greenstein, D., Mann, B. E., Green, C. J., and Motterlini, R. (2006). Modulation of thrombin-induced neuroinflammation in bv-2 microglia by carbon monoxide-releasing molecule 3. J. Pharmacol. Exp. Ther. 318, 1315-1322. doi: 10.1124/jpet.106.104729

Bathoorn, E., Slebos, D. J., Postma, D. S., Koeter, G. H., van Oosterhout, A. J., van der Toorn, M., et al. (2007). Anti-inflammatory effects of inhaled carbon monoxide in patients with copd: a pilot study. Eur. Respir. J. 30, 1131-1137. doi: 10.1183/09031936.00163206

Beckman, J. D., Belcher, J. D., Vineyard, J. V., Chen, C., Nguyen, J., Nwaneri, M. O., et al. (2009). Inhaled carbon monoxide reduces leukocytosis in a murine model of sickle cell disease. Am. J. Physiol. Heart Circ. Physiol. 297, H1243-H1253. doi: 10.1152/ajpheart.00327.2009

Belcher, J. D., Young, M., Chen, C., Nguyen, J., Burhop, K., Tran, P., et al. (2013). Mp4co, a pegylated hemoglobin saturated with carbon monoxide, is a modulator of ho-1, inflammation, and vaso-occlusion in transgenic sickle mice. Blood 122, 2757-2764. doi: 10.1182/blood-201302-486282

Chen, B., Guo, L., Fan, C., Bolisetty, S., Joseph, R., Wright, M. M., et al. (2009). Carbon monoxide rescues heme oxygenase-1-deficient mice from arterial thrombosis in allogeneic aortic transplantation. Am. J. Pathol. 175, 422-429. doi: 10.2353/ajpath.2009.081033

Cheng, S., Lyass, A., Massaro, J. M., O’Connor, G. T., Keaney, J. F. Jr., and Vasan, R. S. (2010). Exhaled carbon monoxide and risk of metabolic syndrome and cardiovascular disease in the community. Circulation 122, 1470-1477. doi: 10.1161/CIRCULATIONAHA.110.941013

Chin, B. Y., Jiang, G., Wegiel, B., Wang, H. J., Macdonald, T., Zhang, X. C., et al. (2007). Hypoxia-inducible factor 1alpha stabilization by carbon monoxide results in cytoprotective preconditioning. Proc. Natl. Acad. Sci. U.S.A. 104, 5109-5114. doi: 10.1073/pnas.06096 11104

Clark, J. E., Naughton, P., Shurey, S., Green, C. J., Johnson, T. R., Mann, B. E., et al. (2003). Cardioprotective actions by a watersoluble carbon monoxide-releasing molecule. Circ. Res. 93, e2-e8. doi: 10.1161/01.RES.0000084381. 86567.08

Coburn, R. F., Blakemore, W. S., and Forster, R. E. (1963). Endogenous carbon monoxide production in man. J. Clin. Invest. 42, 1172-1178. doi: 10.1172/JCI104802

De Backer, O., Elinck, E., Blanckaert, B., Leybaert, L., Motterlini, R., and Lefebvre, R. A. (2009). Water-soluble co-releasing molecules reduce the 
development of postoperative ileus via modulation of mapk/ho-1 signalling and reduction of oxidative stress. Gut 58, 347-356. doi: 10.1136/gut.2008.155481

Dioum, E. M., Rutter, J., Tuckerman, J. R., Gonzalez, G., Gilles-Gonzalez, M. A., and McKnight, S. L. (2002). Npas2: a gas-responsive transcription factor. Science 298, 2385-2387. doi: 10.1126/science. 1078456

Douglas, C. G., Haldane, J. S., and Haldane, J. B. (1912). The laws of combination of haemoglobin with carbon monoxide and oxygen. J. Physiol. 44, 275-304. doi: 10.1113/jphysiol.1912.sp0 01517

Ferenbach, D. A., Nkejabega, N. C., McKay, J., Choudhary, A. K., Vernon, M. A., Beesley, M. F., et al. (2011). The induction of macrophage hemeoxygenase- 1 is protective during acute kidney injury in aging mice. Kidney Int. 79, 966-976. doi: $10.1038 / \mathrm{ki} .2010 .535$

Freitas, A., Alves-Filho, J. C., Secco, D. D., Neto, A. F., Ferreira, S. H., Barja-Fidalgo, C., et al. (2006). Heme oxygenase/carbon monoxidebiliverdin pathway down regulates neutrophil rolling, adhesion and migration in acute inflammation. Br. J. Pharmacol. 149, 345-354. doi: 10.1038/sj.bjp.0706882

James, E. B., Vreman, H. J., Wong, R. J., Stevenson, D. K., Vichinsky, E., Schumacher, L., et al. (2010). Elevated exhaled carbon monoxide concentration in hemoglobinopathies and its relation to red blood cell transfusion therapy. Pediatr. Hematol. Oncol. 27, 112-121. doi: 10.3109/08880010903536227

Kuramitsu, K., Gallo, D., Yoon, M., Chin, B. Y., Csizmadia, E., Hanto, D. W., et al. (2011). Carbon monoxide enhances early liver regeneration in mice after hepatectomy. Hepatology 53, 2016-2026. doi: 10.1002/hep.24317

Lakkisto, P., Kyto, V., Forsten, H., Siren, J. M., Segersvard, H., Voipio-Pulkki, L. M., et al. (2010). Heme oxygenase- 1 and carbon monoxide promote neovascularization after myocardial infarction by modulating the expression of hif-lalpha, sdf-1alpha and vegf-b. Eur. J. Pharmacol. 635, 156-164. doi: 10.1016/j.ejphar.2010.02.050

Lancel, S., Hassoun, S. M., Favory, R., Decoster, B., Motterlini, R., and Neviere, R. (2009). Carbon monoxide rescues mice from lethal sepsis by supporting mitochondrial energetic metabolism and activating mitochondrial biogenesis. J. Pharmacol. Exp. Ther. 329, 641-648. doi: 10.1124/jpet.108.148049

Lee, S. S., Gao, W., Mazzola, S., Thomas, M. N., Csizmadia, E., Otterbein, L. E., et al. (2007). Heme oxygenase-1, carbon monoxide, and bilirubin induce tolerance in recipients toward islet allografts by modulating $\mathrm{t}$ regulatory cells. FASEB J. 21, 3450-3457. doi: 10.1096/fj.07$8472 \mathrm{com}$

Lin, H. H., Chen, Y. H., Yet, S. F., and Chau, L. Y. (2009). After vascular injury, heme oxygenase-1/carbon monoxide enhances re-endothelialization via promoting mobilization of circulating endothelial progenitor cells. J. Thromb. Haemost. 7, 1401-1408. doi: 10.1111/j.1538-7836.2009.03478.x

Marazioti, A., Bucci, M., Coletta, C., Vellecco, V., Baskaran, P., Szabo, C., et al. (2011).
Inhibition of nitric oxide-stimulated vasorelaxation by carbon monoxide-releasing molecules. Arterioscler. Thromb. Vasc. Biol. 31, 2570-2576. doi: 10.1161/ATVBAHA.111.229039

Mayr, F. B., Spiel, A., Leitner, J., Marsik, C., Germann, P., Ullrich, R., et al. (2005). Effects of carbon monoxide inhalation during experimental endotoxemia in humans. Am. J. Respir. Crit. Care Med. 171, 354-360. doi: $10.1164 / \mathrm{rccm} .200404-$ $446 \mathrm{OC}$

Megias, J., Busserolles, J., and Alcaraz, M. J. (2007). The carbon monoxide-releasing molecule corm2 inhibits the inflammatory response induced by cytokines in caco-2 cells. Br. J. Pharmacol. 150, 977-986. doi: 10.1038/sj.bjp.0707184

Motterlini, R., Clark, J. E., Foresti, R., Sarathchandra, P., Mann, B. E., and Green, C. J. (2002). Carbon monoxide-releasing molecules: characterization of biochemical and vascular activities. Circ. Res. 90, E17-E24. doi: 10.1161/hh0202.104530

Motterlini, R., and Otterbein, L. E. (2010). The therapeutic potential of carbon monoxide. Nat. Rev. Drug Discov. 9, 728-743. doi: 10.1038/nrd3228

Motterlini, R., Sawle, P., Hammad, J., Bains, S., Alberto, R., Foresti, R., et al. (2005). Corm-a1: a new pharmacologically active carbon monoxidereleasing molecule. FASEB J. 19, 284-286. doi: 10.1096/fj.04-2169fje

Ogawa, T., Hanggi, D., Wu, Y., Michiue, H., Tomizawa, K., Ono, S., et al. (2011). Protein therapy using heme-oxygenase-1 fused to a polyarginine transduction domain attenuates cerebral vasospasm after experimental subarachnoid hemorrhage. J. Cereb. Blood Flow Metab. 31, 2231-2242. doi: $10.1038 / \mathrm{jcbfm} .2011 .87$

Otterbein, L. E., Kolls, J. K., Mantell, L. L. Cook, J. L., Alam, J., and Choi, A. M. (1999). Exogenous administration of heme oxygenase1 by gene transfer provides protection against hyperoxia-induced lung injury. J. Clin. Invest. 103, 1047-1054. doi: 10.1172/JCI5342

Otterbein, L. E., Zuckerbraun, B. S., Haga, M., Liu, F., Song, R., Usheva, A., et al. (2003). Carbon monoxide suppresses arteriosclerotic lesions associated with chronic graft rejection and with balloon injury. Nat. Med. 9, 183-190. doi: 10.1038/nm817

Park, M. K., Kim, C. H., Kim, Y. M., Kang, Y. J., Kim, H. J., Kim, H. J., et al. (2007). Akt-dependent heme oxygenase-1 induction by ns-398 in c6 glial cells: a potential role for co in prevention of oxidative damage from hypoxia. Neuropharmacology 53, 542-551. doi: 10.1016/j.neuropharm.2007. 06.022

Piantadosi, C. A., Carraway, M. S., Babiker, A., and Suliman, H. B. (2008). Heme oxygenase1 regulates cardiac mitochondrial biogenesis via nrf2-mediated transcriptional control of nuclear respiratory factor-1. Circ. Res. 103, 1232-1240. doi: 10.1161/01.RES.0000338597.71702.ad

Poss, K. D., and Tonegawa, S. (1997). Reduced stress defense in heme oxygenase 1-deficient cells. Proc. Natl. Acad. Sci. U.S.A. 94, 10925-10930. doi: 10.1073/pnas.94.20.10925

Schallner, N., Romao, C. C., Biermann, J., Lagreze, W. A., Otterbein, L. E., Buerkle, H., et al. (2013). Carbon monoxide abrogates ischemic insult to neuronal cells via the soluble guanylate cyclase-cgmp pathway. PLoS ONE 8:e60672. doi: 10.1371/journal.pone.0060672
Sjostrand, T. (1949). Endogenous formation of carbon monoxide in man. Nature 164,580 . doi: 10.1038/164580a0

Song, R., Kubo, M., Morse, D., Zhou, Z., Zhang, X., Dauber, J. H., et al. (2003). Carbon monoxide induces cytoprotection in rat orthotopic lung transplantation via anti-inflammatory and antiapoptotic effects. Am. J. Pathol. 163, 231-242. doi: 10.1016/S0002-9440(10)63646-2

Song, R., Zhou, Z., Kim, P. K., Shapiro, R. A., Liu, F., Ferran, C., et al. (2004). Carbon monoxide promotes fas/cd95-induced apoptosis in jurkat cells. J. Biol. Chem. 279, 44327-44334. doi: 10.1074/jbc.M406105200

Suliman, H. B., Carraway, M. S., Ali, A. S., Reynolds, C. M., Welty-Wolf, K. E., and Piantadosi, C. A. (2007). The co/ho system reverses inhibition of mitochondrial biogenesis and prevents murine doxorubicin cardiomyopathy. J. Clin. Invest. 117, 3730-3741. doi: 10.1172/JCI32967

Taille, C., El-Benna, J., Lanone, S., Boczkowski, J., and Motterlini, R. (2005). Mitochondrial respiratory chain and nad(p)h oxidase are targets for the antiproliferative effect of carbon monoxide in human airway smooth muscle. J. Biol. Chem. 280, 25350-25360. doi: 10.1074/jbc.M503512200

Tayem, Y., Johnson, T. R., Mann, B. E., Green, C. J., and Motterlini, R. (2006). Protection against cisplatin-induced nephrotoxicity by a carbon monoxide-releasing molecule. Am. J. Physiol. Renal Physiol. 290, F789-F794. doi: 10.1152/ajprenal.00363.2005

Tenhunen, R., Marver, H. S., and Schmid, R. (1968). The enzymatic conversion of heme to bilirubin by microsomal heme oxygenase. Proc. Natl. Acad. Sci. U.S.A. 61, 748-755. doi: 10.1073/pnas.61.2.748

Tsoyi, K., Ha, Y. M., Kim, Y. M., Lee, Y. S., Kim, H. J., Kim, H. J., et al. (2009). Activation of ppargamma by carbon monoxide from corm-2 leads to the inhibition of inos but not cox-2 expression in lps-stimulated macrophages. Inflammation 32, 364-371. doi: 10.1007/s10753-0099144-0

Tsuchihashi, S., Zhai, Y., Bo, Q., Busuttil, R. W., and Kupiec-Weglinski, J. W. (2007). Heme oxygenase1 mediated cytoprotection against liver ischemia and reperfusion injury: inhibition of type-1 interferon signaling. Transplantation 83, 1628-1634. doi: 10.1097/01.tp.0000266917.39958.47

Tsui, T. Y., Obed, A., Siu, Y. T., Yet, S. F., Prantl, L., Schlitt, H. J., et al. (2007). Carbon monoxide inhalation rescues mice from fulminant hepatitis through improving hepatic energy metabolism. Shock 27, 165-171. doi: 10.1097/01.shk.0000239781.71516.61

Urquhart, P., Rosignoli, G., Cooper, D., Motterlini, R., and Perretti, M. (2007). Carbon monoxide-releasing molecules modulate leukocyte-endothelial interactions under flow. J. Pharmacol. Exp. Ther. 321, 656-662. doi: 10.1124/jpet.106.117218

Vadori, M., Seveso, M., Besenzon, F., Bosio, E., Tognato, E., Fante, F., et al. (2009). In vitro and in vivo effects of the carbon monoxidereleasing molecule, corm- 3 , in the xenogeneic pig-to-primate context. Xenotransplantation 16, 99-114. doi: 10.1111/j.1399-3089.2009.00521.x

Verma, A., Hirsch, D. J., Glatt, C. E., Ronnett, G. V., and Snyder, S. H. (1993). Carbon monoxide: a 
putative neural messenger. Science 259, 381-384. doi: 10.1126/science.7678352

Vieira, H. L., Queiroga, C. S., and Alves, P. M. (2008). Pre-conditioning induced by carbon monoxide provides neuronal protection against apoptosis. J. Neurochem. 107, 375-384. doi: 10.1111/j.14714159.2008.05610.x

Vos, R., Cordemans, C., Vanaudenaerde, B. M., De Vleeschauwer, S. I., Schoonis, A., Van Raemdonck, D. E., et al. (2009). Exhaled carbon monoxide as a noninvasive marker of airway neutrophilia after lung transplantation. Transplantation 87, 1579-1583. doi: 10.1097/TP.0b013e3181a $4 \mathrm{e} 69 \mathrm{c}$

Wang, B., Cao, W., Biswal, S., and Dore, S. (2011). Carbon monoxide-activated nrf2 pathway leads to protection against permanent focal cerebral ischemia. Stroke 42, 2605-2610. doi: 10.1161/STROKEAHA.110.607101

Wang, H. Q., Xu, Y. X., and Zhu, C. Q. (2012). Upregulation of heme oxygenase-1 by acteoside through erk and pi3 k/akt pathway confer neuroprotection against beta-amyloid-induced neurotoxicity. Neurotox. Res. 21, 368-378. doi: 10.1007/s12640-011-9292-5

Wang, X. M., Kim, H. P., Nakahira, K., Ryter, S. W., and Choi, A. M. (2009). The heme oxygenase$1 /$ carbon monoxide pathway suppresses tlr4 signaling by regulating the interaction of tlr 4 with caveolin-1. J. Immunol. 182, 3809-3818. doi: 10.4049/jimmunol.0712437

Wegiel, B., Gallo, D., Csizmadia, E., Harris, C., Belcher, J., Vercellotti, G. M., et al. (2013).
Carbon monoxide expedites metabolic exhaustion to inhibit tumor growth. Cancer Res. 73, 7009-7021. doi: 10.1158/0008-5472.CAN-13-1075

Yabluchanskiy, A., Sawle, P., Homer-Vanniasinkam, S., Green, C. J., Foresti, R., and Motterlini, R. (2012). Corm-3, a carbon monoxide-releasing molecule, alters the inflammatory response and reduces brain damage in a rat model of hemorrhagic stroke. Crit. Care Med. 40, 544-552. doi: 10.1097/CCM.0b013e31822f0d64

Yin, H., Li, X., Gong, Q., Jin, X., Gu, H., Yuan, B., et al. (2010). Heme oxygenase-1 upregulation improves lipopolysaccharide-induced acute lung injury involving suppression of macrophage migration inhibitory factor. Mol. Immunol. 47, 2443-2449. doi: 10.1016/j.molimm.2010. 06.013

Zeynalov, E., and Dore, S. (2009). Low doses of carbon monoxide protect against experimental focal brain ischemia. Neurotox. Res. 15, 133-137. doi: 10.1007/s12640-009-9014-4

Zhang, F., Wang, S., Zhang, M., Weng, Z., Li, P., Gan, Y., et al. (2012). Pharmacological induction of heme oxygenase-1 by a triterpenoid protects neurons against ischemic injury. Stroke 43, 1390-1397. doi: 10.1161/STROKEAHA.111. 647420

Zhang, J., Yao, X., Yu, R., Bai, J., Sun, Y., Huang, M., et al. (2010). Exhaled carbon monoxide in asthmatics: a meta-analysis. Respir. Res. 11:50. doi: 10.1186/1465-9921-11-50

Zuckerbraun, B. S., Billiar, T. R., Otterbein, S. L., Kim, P. K., Liu, F., Choi, A. M., et al. (2003).
Carbon monoxide protects against liver failure through nitric oxide-induced heme oxygenase 1 . J. Exp. Med. 198, 1707-1716. doi: 10.1084/jem.200 31003

Zuckerbraun, B. S., Chin, B. Y., Bilban, M., D’Avila, J. C., Rao, J., Billiar, T. R., et al. (2007). Carbon monoxide signals via inhibition of cytochrome $c$ oxidase and generation of mitochondrial reactive oxygen species. FASEB J. 21, 1099-1106. doi: 10.1096/fj.06-6644com

Conflict of Interest Statement: The authors declare that the research was conducted in the absence of any commercial or financial relationships that could be construed as a potential conflict of interest.

Received: 24 November 2014; paper pending published: 03 December 2014; accepted: 11 January 2015; published online: 03 February 2015.

Citation: Schallner N and Otterbein LE (2015) Friend or foe? Carbon monoxide and the mitochondria. Front. Physiol. 6:17. doi: 10.3389/fphys.2015.00017

This article was submitted to Mitochondrial Research, a section of the journal Frontiers in Physiology.

Copyright (c) 2015 Schallner and Otterbein. This is an open-access article distributed under the terms of the Creative Commons Attribution License (CC BY). The use, distribution or reproduction in other forums is permitted, provided the original author(s) or licensor are credited and that the original publication in this journal is cited, in accordance with accepted academic practice. No use, distribution or reproduction is permitted which does not comply with these terms. 